\title{
КОМПЛЕКСНАЯ ОЦЕНКА ЭФФЕКТИВНОСТИ ИСПОЛЬЗОВАНИЯ И РАСПОРЯЖЕНИЯ НЕДВИЖИМОСТЬЮ
}

\author{
О. В. Липатова', С. Л. Шатров ${ }^{2}$
}

\author{
${ }^{1}$ К. э. н., доцент, заведующий карфедрой «Экономика транспорта» учреждения образования \\ «Белорусский государственный университет транспорта», Гомель, Беларусь, e-mail: gef@bsut.by \\ ${ }^{2}$ К. э. н., доцент, заведующий кафредрой «Учетные системы и технологии бизнес-менеджмента» учреждения образования \\ «Белорусский государственный университет транспорта», Гомель, Беларусь, е-mail: SLChatrov@yandex.ru
}

\begin{abstract}
Реферат
Рассматривается методика оценки эффективности использования и распоряжения объектами недвижимого имущества. Приводится система экономических показателей, характеризующих эффективность использования площадей различного характера использования. Для объектов недвижимости, использование которых является экономически неэффективным, приведена методика оценки целесообразности и расчета экономического эффекта при отчуждении либо вовлечении в хозяйственный оборот.
\end{abstract}

Ключевые слова: производственная площадь, недвижимое имущество, оценка эффективности использования, объект недвижимости, распоряжение имуществом.

\section{COMPREHENSIVE ASSESSMENT OF THE EFFECTIVENESS OF USE AND DISPOSAL OF REAL ESTATE}

\section{Abstract}

\section{O. V. Lipatova, S. L. Shatrov}

The technique of estimation of efficiency of use and the order of objects of real estate is considered. A system of economic indicators characterizing the efficiency of the use of areas of different types of use. For real estate, the use of which is economically inefficient, the method of assessing the feasibility and calculation of the economic effect of alienation or involvement in economic turnover.

Keywords: production area, real estate, assessment of the effectiveness of use, real estate, property management.

\section{Введение}

Эффективное использование недвижимого имущества, находящегося в распоряжении предприятий, является одним из важнейших критериев качества управления в современных условиях хозяйствования. В связи с общим спадом производства появились избыточные площади, содержание которых ухудшает и без того неустойчивое экономическое положение предприятий. Затраты на содержание избыточных площадей увеличивают себестоимость продукции, снижая ее конкурентоспособность и конкурентоспособность предприятия в целом.

Основным признаком «эффективного собственника» является его высокая доходность, обеспеченная результативностью хозяйственной деятельности. При этом интересует его, прежде всего, эффективность использования недвижимого имущества как главного элемента собственного имущества организации.

Оценка эффективности используемого недвижимого имущества наиболее актуальным становится для предприятий и организаций, имеющих большое количество площадей различного назначения. При этом рациональное их использование позволяет не только снизить затраты на содержание, но и увеличить доходы в случае сдачи в аренду, а также повысить эффективность производственнохозяйственной деятельности. Для решения этой задачи необходимо регулярно оценивать и контролировать эффективность использования площадей, а также своевременно обосновывать направления распоряжения неэффективно используемыми в хозяйственной деятельности объектами [1].

Методика оценки эффективности использования недвижимого имущества

Разработка методики оценки эфффективности использования недвижимого имущества требует деления его на группы в зависимости от назначения и реального использования в хозяйственной деятельности субъекта. Так, для целей аналитического исследования целесообразным является деление всех производственных площадей на площади производственного, коммерческого, социального назначения.

Под производственными площадями понимается часть площадей хозяйствующих субъектов, на которых осуществляются все технологические процессы, связанные с изготовлением продукции (работ, услуг). Под площадями, имеющими коммерческий характер использования, понимаются здания и помещения, сооружения (или их части), целью использования которых является извлечение прибыли. Для социального характера использования площадей характерна их способность удовлетворять материальные и эстетические потребности человека, обеспечивая выполнение потребительской функции личности.

Так, использование площадей оценивается с помощью системы показателей, которые в совокупности определяют критерии оценки эффективности использования площадей различного назначения.

Все показатели эффективности использования площадей различного назначения связи классифицируют по следующим группам:

- структурные показатели: коэффициенты профильного использования площадей, непрофильного использования площадей и коэфффициенты аренды;

- показатели производственного использования площадей: коэффициент экстенсивного использования производственной площади, коэффициент интенсивного использования производственной площади, интегральный коэффициент использования производственной площади и коэффициент загрузки производственной площади;

- показатели эффективности использования площадей: коэффи-

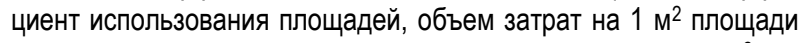
зданий, прибыль от деятельности по направлениям на 1 м² используемой площади, стоимость теплосодержания $1 \mathrm{~m}^{2}$ площадей по подразделениям.

1. Коэффициент профильного использования площадей характеризует долю площадей различного назначения в их общем объеме:

- социального характера использования:

$$
k_{\text {профр. исп. }}^{\text {cou }}=\frac{S^{\mathrm{cou}}}{S}
$$


- коммерческого характера использования:

$$
k_{\text {проф. исп. }}^{\text {ком }}=\frac{S^{\text {КОм }}}{S}
$$

- производственного характера использования:

$$
k_{\text {профр. исп. }}^{п р}=\frac{S^{n p}}{S}
$$

где $S^{\text {соu }}, S^{\text {ком }}, S^{\text {пр }}$ - сумма площадей зданий, непосредственно используемых в социальных, коммерческих, производственных целях соответственно, м²;

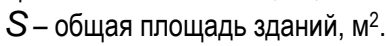

2. Коэффициент непрофильного использования площадей характеризует долю площадей обслуживающего характера (административного использования и бытового использования) в их общем объеме:

- административного использования:

$$
k_{\text {непроф. }}^{\text {адм }}=\frac{S^{a \partial M}}{S}
$$

- бытового использования:

$$
k_{\text {непрофр. }}^{\text {быт }}=\frac{S^{\text {быm }}}{S}
$$

где $S^{\text {адм }}, S^{б ы m}$ - сумма площадей зданий, непосредственно используемых в административных и санитарно-бытовых целях соответственно, м²;

3. Коэффициенты аренды характеризует долю площадей, сдаваемых в аренду в структуре площадей различного назначения:

- общий коэфффициент аренды:

$$
k_{a p}=\frac{S_{a p}}{S} ;
$$

- коэффициент аренды зданий социального характера использования:

$$
k_{a p}^{c o u}=\frac{S_{\text {cou }}^{a p}}{S_{c o u}},
$$

где $S$ - общая площадь зданий, м²;

$S_{a p}$ - площади зданий, сданных в аренду, м²;

$S_{c o u}$ - площадь зданий соответственно социального характера использования соответственно, м².

$$
S_{c o u}^{a p} \text { - площади зданий социального характера использования }
$$
сданных, в аренду, м².

4. Показатели использования производственной площади характеризуют количественные и качественные параметры использования производственных площадей в производственном процессе:

а) коэффициент экстенсивного использования производственной площади:

$$
k_{\text {пл.э. }}=\frac{T_{p} k_{C M}}{365},
$$

где $T_{p}$ - количество рабочих дней в году,

$k_{c м}$ - коэффициент сменности работы оборудования;

б) коэффициент интенсивного использования производственной площади:

$$
k_{\text {пл.и. }}=\frac{S_{э ф p}}{S_{п р}},
$$

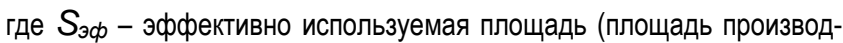
ственных цехов), м $^{2}$

$S_{n р}$ - размер производственной площади, м²;

в) интегральный коэфффициент использования производственной площади:

$$
k_{\text {пл.инт. }}=k_{\text {пл.э. }} k_{\text {пл.и. }} \text {; }
$$

г) коэфффициент загрузки производственной площади:

$$
k_{\text {загр } s}=\frac{V}{S_{\text {эфр }}},
$$

где $V$ - объем выполненных работ:

д) производственная площадь, приходящаяся на одну единищу оборудования:

$$
S_{\text {об }}=\frac{S_{п р}}{k_{\text {усm }}},
$$

где $k_{\text {уст }}$ - количество установленного оборудования.

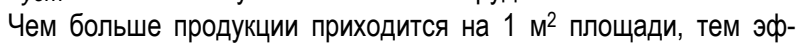
фективнее она используется.

5. Коэффициент использования площадей - отражает объем деятельности предприятия в стоимостных показателях (выручка) по направлениям деятельности и в целом на м² располагаемых площадей:

- деятельность социального характера:

$$
k_{\text {u. . }}^{\text {cmoum }}=\frac{B^{\mathrm{cou}}}{S_{\text {cou }}} ;
$$

- деятельность коммерческого характера:

$$
k_{\text {u. }}^{\text {cmouм }}=\frac{B^{\text {КОМ }}}{S_{\text {КОм }}},
$$

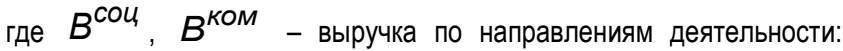
социального, коммерческого характера соответственно.

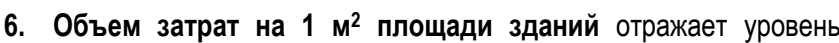
затрат по содержанию недвижимости различного назначения:

- социального характера использования:

$$
3_{M^{2}}^{\text {cou }}=\frac{3_{\text {umyu }}^{\text {cou }}}{S_{\text {cou }}}
$$

- коммерческого характера использования:

$$
3_{M^{2}}^{\text {КОМм }}=\frac{3_{\text {ИМущ }}^{\text {КОМм }}}{S_{\text {КОмм }}}
$$

- производственного характера использования:

$$
3_{M^{2}}^{n p}=\frac{3_{u м y щ}^{n p}}{S_{п p}}
$$

где $3_{\text {имущ, }}^{c o u} 3_{\text {имущ }}^{\text {комм }} 3_{\text {имущ - затраты на содержание недви- }}^{\text {пр }}$ жимости социального, коммерческого, производственного характера использования соответственно, руб.;

$S_{c o u}, S_{\text {ком }}, S_{\text {пр - площадь зданий социального, коммерче- }}$ ского, производственного характера использования соответственно, м².

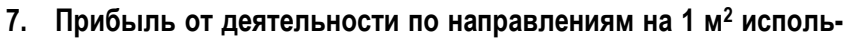
зуемой площади характеризует величину прибыли, приходящейся на 1 м² недвижимости различного назначения: 
- от деятельности социального характера:

$$
\Pi_{\text {cou }}^{1 \mathrm{M}^{2}}=\frac{\Pi_{\mathrm{cou}}}{S_{\mathrm{cou}}}
$$

- от деятельности коммерческого характера:

$$
\Pi_{\text {КОMм }}^{1 \mathrm{M}^{2}}=\frac{\Pi_{\text {КOM }}}{S_{\text {KOM }}} ;
$$

- от деятельности производственного характера:

$$
\Pi_{\Pi p .}^{1 м^{2}}=\frac{\Pi_{п р}}{S_{\Pi p}},
$$

где $П_{\text {сои, }}, П_{к о м}, П_{п р}-$ прибыль от осуществления деятельности социального, коммерческого, производственного характера соответственно.

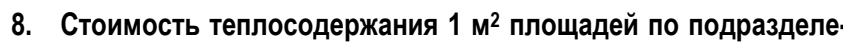
ниям характеризует удельные теплозатраты по содержанию площадей различного характера их использования

$$
C_{\text {содерж. }}^{1 M^{2}}=\frac{3_{T \ni}}{S}
$$

где 3 тэ-затраты на теплоэнергию, руб.

В таблице 1 представлена обобщающая информация по применению системы показателей, используемой для площадей различного характера использования.

Предлагаемая система показателей позволяет не только оценить эффективность использования производственных площадей но и выявить те площади, использование которых в хозяйственном обороте является экономически нецелесообразным. Для таких объектов недвижимости применяется методика оценки целесообразности и расчета экономического эффекта при отчуждении или вовлечении в хозяйственный оборот объектов недвижимого имущества и земельных участков. В качестве экономического эфффекта от реализации выбранного направления использования недвижимого иму-

\begin{tabular}{|c|c|c|c|}
\hline Показатель & 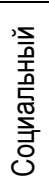 & 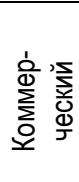 & 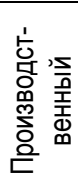 \\
\hline $\begin{array}{l}\text { 1. Коэффициент профильного } \\
\text { использования площадей }\end{array}$ & + & + & + \\
\hline $\begin{array}{l}\text { 2. Коэффиициент непрофильного } \\
\text { использования площадей }\end{array}$ & + & & + \\
\hline 3. Коэфффициенты аренды & + & & \\
\hline $\begin{array}{l}\text { 4. Показатели использования } \\
\text { производственной площади }\end{array}$ & & & + \\
\hline $\begin{array}{l}\text { 5. Коэффицциент использования } \\
\text { площадей }\end{array}$ & + & + & \\
\hline $\begin{array}{l}\text { 6. Объем затрат на м² } \\
\text { площади зданий }\end{array}$ & + & + & + \\
\hline $\begin{array}{l}7 \text { Прибыль от деятельности } \\
\text { по направлениям на м² } \\
\text { используемой площади }\end{array}$ & + & + & \\
\hline $\begin{array}{l}\text { 8. Стоимость теплосодержания } \\
1 \text { м² площадей по подразделениям }\end{array}$ & + & + & + \\
\hline
\end{tabular}
щества принята окупаемость понесенных затрат.

Таблица 1 - Матрица обобщения показателей для оценки использования недвижимости

В предлагаемой методике предусмотрены следующие основные варианты хозяйственных операций с объектами недвижимого имущества:

- отчуждение в установленном порядке на аукционе, по конкурсу, без проведения аукциона либо конкурса;

- безвозмездная передача объектов имущества субъектам государственной формы собственности;

- безвозмездная передача объектов имущества в частную собственность;
- использование объектов имущества в собственных целях после проведения реконструкции, капитального ремонта, перепрофилирования и иных мероприятий;

- внесение объектов имущества в уставный капитал (фонд) других организаций;

- ликвидация объектов недвижимого имущества;

- передача неиспользуемых земель в коммунальную собственность;

- уточнение целевого назначения земельных участков в связи с их фактическим использованием [2-4].

Результат от реализации объекта недвижимого имущества определяется по формуле:

$$
\pm P=C P-O C-C 3_{\partial е м}-C 3_{\text {рем }}-3_{C O \Pi,}
$$

где $\pm P$ - результат от реализации (прибыль + , убыток - ), руб.;

CP - средства от реализации, остающиеся в распоряжении предприятия, руб.;

OC - остаточная стоимость объекта недвижимого имущества, руб.;

CЗдем - сметные (плановые) затраты по демонтажу машин и оборудования при его необходимости, включая разработку проектносметной документации, руб. при необходимости;

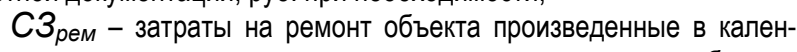
дарном году до момента принятия решения о реализации объекта, (используются фактические данные бухгалтерского учета);

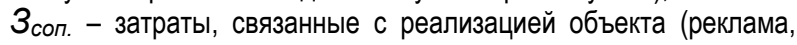
объявления, проведение аукциона и т. п.).

Экономически эфффективными считаются операции по реализации неиспользуемого имущества если рассчитанный результат положительный (прибыль) или равен нулю, если результат отрицательный (убыток) - необходимо дополнительно рассчитать сумму оптимизации затрат за счет выбытия имущества.

Сумма оптимизации затрат за счет выбытия объекта недвижимого имущества, повышающая экономическую эффективность операции по реализации объекта, рассчитывается по формуле:

$P_{1}=-P+C P_{\text {рем год }}+C 3_{\text {содерж год }}+C 3_{\text {сниж налог нагр }}$

где $P_{1}$ - дополнительный результат от реализации (прибыль +, убыток -), руб:;

C3 рем год - годовая сумма затрат по ремонту объекта недвижимого имущества в текущем году, включая разработку, при необходимости, проектно-сметной документации, руб. Рассчитывается по двум вариантам: 1) на основании бухгалтерских данных за предыдущий календарный год или за предшествующие годы, скорректированных на индекс изменения цен (индексах изменения стоимости в строительстве); 2) на основании сметных (плановых) расчетов затрат на ремонт объекта недвижимости;

C3 содерж год - годовая сумма затрат по содержанию объекта определяется на основании бухгалтерских данных за предыдущий календарный год, скорректированных на индекс изменения потребительских цен. В затраты по содержанию включаются: стоимость энергии, воды, пара, расходы по уборке помещений, расходы по охране здания, затраты по противопожарной безопасности и другие затраты;

C3 сниж налог нагр - снижение налоговой нагрузки по налогу на недвижимость и земельному налогу;

В случаях отнесения подлежащего безвозмездной передаче объекта недвижимости к неиспользуемому, неэффективно используемому имуществу, такая передача является экономически обоснованным решением. При этом размер эффекта зависит от снижения затрат за счет безвозмездной передачи объекта и включает:

- $\quad$ отсутствие затрат по проведению ремонтов объекта. Годовая сумма затрат по ремонту объекта в случае необходимости его проведения в расчетном периоде определяется по двум вариантам;

- $\quad$ на основании бухгалтерских данных за предыдущий календарный год или за предшествующие годы, скорректированных на индекс изменения цен (индексах изменения стоимости в строительстве);

- на основании сметных (плановых) расчетов затрат на ремонт объекта недвижимости;

- отсутствие затрат по текущему содержанию объекта (кроме затрат на ремонт). В затраты по содержанию включаются: стоимость энергии, воды, пара, расходы по уборке помещений, расходы по охране здания, затраты по противопожарной безопасности и др. и определяется на основании бухгалтерских данных 
за предыдущий календарный год, скорректированных на индекс изменения потребительских цен;

- снижение налоговой нагрузки по налогу на недвижимость и земельному налогу.

Результат от безвозмездной передачи объекта недвижимого имущества определяется по формуле:

$$
-P_{\text {бпе }}=\mathrm{OC}+C 3_{\text {дем }}+C 3_{\text {рем }}+C 3_{\text {усл }},
$$

где $P_{\text {бпа }}$ - результат от безвозмездной передачи объекта недвижимого имущества, руб.;

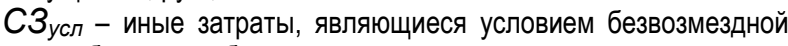
передачи объектов, руб.

Результат от безвозмездной передачи недвижимого имущества из республиканской собственности в частную собственность определяется по формуле:

$$
-P_{\text {бпч }}=O C+C 3_{\text {дем }}
$$

где $P_{\text {бпч }}$ - результат от безвозмездной передачи недвижимого имущества из республиканской собственности в частную собственность (убыток), руб.

В случаях если остаточная стоимость недвижимого имущества равна нулю, а также при отнесении подлежащего безвозмездной передаче объекта недвижимости к неиспользуемому, неэффрективно используемому имуществу, то такая передача является экономически обоснованным решением.

При проведения реконструкции, капитального ремонта, перепрофилирования объектов имущества необходимы дополнительные затраты на:

- разработку и обоснование проекта, подготовку проектной документации, проведение технической, технологической и экономической разработки проектной документации, расчета объемов финансирования;

- проведение реконструкции, капитального ремонта здания, обновление технологического оборудования.

Одним из направлений распоряжения имуществом является внесение объектов недвижимого имущества в уставный капитал (фонд) других организаций.

Затратами, связанными с внесением объектов недвижимого имущества в уставный капитал другой организации, являются:

- затраты по ремонту (плановые или фрактические);

- затраты по демонтажу и вывозу к месту хранения машин и оборудования, производственного и хозяйственного инвентаря, находящихся внутри здания (плановые или фактические).

Результат от внесения объекта недвижимого имущества в уставный капитал другой организации определяется по формуле:

$$
\pm P_{\text {вук }}=C B K-O C-C 3_{\text {дем }}-C 3_{\text {рем }},
$$

где $\pm P_{\text {вук }}$ - результат от передачи здания в уставный капитал другой организации (прибыль +, убыток-), руб.;

CBК - стоимость объекта, передаваемого в уставный капитал другой организации, руб.;

ОС - остаточная стоимость объекта недвижимого имущества, передаваемого в уставный капитал другой организации, руб.

Если результат от передачи отрицательный (убыток), то он погашается за счет доходов (дивидендов), а также оптимизации затрат за счет внесения объектов в уставный капитал другой организации.

В случае ликвидации объектов недвижимого имущества основными затратами являются:

- затраты по уничтожению (сносу, демонтажу) имущества, включая при необходимости проведение технического обследования, разработку проектной документации;

- $\quad$ затраты по вывозу строительного мусора к месту его утилизации.

Результат от ликвидации объекта основных средств определяется по формуле:

$$
\pm P_{\text {лик }}=\text { МЦ-OC-3С-3M, }
$$

где $\pm P_{\text {лик }}$ - результат от ликвидации объекта недвижимого имущества (прибыль либо убыток), руб.;

МЦ - стоимость оприходованных материальных ценностей, полученных в результате ликвидации объекта, руб.;

OC - остаточная стоимость объекта недвижимого имущества, руб.;

ЗС - затраты по сносу объекта недвижимого имущества, руб.;

ЗМ - затраты по вывозу строительного мусора, руб.
Если результат от списания объекта недвижимого имущества положительный (прибыль) или равен нулю, то операции по списанию неиспользуемого имущества можно считать экономически эффективными, если результат отрицательный (убыток) - необходимо рассчитать сумму оптимизации затрат за счет выбытия объекта.

В случае передачи неиспользуемых земель в коммунальную собственность затратами, связанными С передачей земельных участков, являются затраты по рекультивации участков (при необходимости) и оформлению землеустроительных документов, необходимых для вынесения соответствующим исполнительным комитетом решения об изъятии земельного участка.

Сумма оптимизации затрат за счет изъятия участка, определяющая экономическую эффективность операции по изъятию объекта, включает:

- прекращение уплаты земельного налога;

- отсутствие капитальных затрат по улучшению земель и затрат по содержанию.

Срок окупаемости затрат, связанных с передачей земельных участков, определяется по формуле:

$$
\mathrm{CO}_{\text {пзу }}=\frac{3 \Pi \mathrm{Y}}{3 \mathrm{H}+K 3}
$$

где $\mathrm{CO}_{\text {пзу }}$ - срок окупаемости затрат, связанных с передачей земельных участков, лет;

ЗПУ - затраты по передаче земельных участков, руб.;

КЗ - годовые затраты по улучшению земель и содержанию, руб.

\section{Заключение}

Таким образом, при использовании предложенного метода расчета календарных планов строительства получаются календарные планы, не требующие корректировки по времени, что значительно сокращает и упрощает процесс их разработки, а значит и сокращает время на проектирование.

\section{Список цитированных источников}

1. Анализ хозяйственной деятельности на железнодорожном транспор-те: учеб. пособие / В. Г. Гизатуллина [и др.] ; под общ. ред. В. Г. Гизатуллиной, Д. А. Панкова ; М-во образования Республики Беларусь, Белорус. гос. ун-т трансп. - Гомель : БелГУТ, 2008. - 368 с.

2. Шатров, С. Л. Аутсорсинг бизнес-процессов транспортных систем / С. Л. Шатров, О. В. Липатова, И. А. Кейзер. - Гомель : БелГУТ, 2017. $-203 \mathrm{c}$.

3. Шатров, С. Л. Направления использования имущества, высвобожденного в результате аутсорсинга / С. Л. Шатров, А. В. Кравченко // Экономический рост Республики Беларусь: глобализация, инновационность, устойчивость: материалы XI Межд. науч.практ. конф. - Минск : БГЭУ, 2018. - С. 523-524.

4. Шатров, С. Л. Научное обоснование направлений распоряжения капитальными строениями, неэффективно используемыми в хозяйственной деятельности / С. Л. Шатров, В. С. Кишкун // Рынок транспортных услуг (проблемы повышения эффективности): Межд. сб. научн. тр. - 2017. - Вып. 10. - С. 326-333.

\section{References}

1. Analiz hozyajstvennoj deyatel'nosti na zheleznodorozhnom transporte: ucheb. posobie / V. G. Gizatullina [i dr.] ; pod obshch. red. V. G. Gizatullinoj, D. A. Pankova ; M-vo obrazovaniya Respubliki Belarus', Belorus. gos. un-t transp. - Gomel' : BelGUT, 2008. - $368 \mathrm{~s}$.

2. SHatrov, S. L. Autsorsing biznes-processov transportnyh sistem / S. L. Shatrov, O. V. Lipatova, I. A. Kejzer. - Gomel' : BelGUT, 2017. $203 \mathrm{~s}$.

3. SHatrov, S. L. Napravleniya ispol'zovaniya imushchestva, vysvobozhdennogo v rezul'tate autsorsinga / S. L. SHatrov, A. V. Kravchenko // Ekonomicheskij rost Respubliki Belarus': globalizaciya, innovacionnost', ustojchivost': materialy XI Mezhd. nauch.-prakt. konf. - Minsk : BGEU, 2018. - S. 523-524.

4. SHatrov, S. L. Nauchnoe obosnovanie napravlenij rasporyazheniya kapital'nymi stroeniyami, neeffektivno ispol'zuemymi v hozyajstvennoj deyatel'nosti / S. L. SHatrov, V. S. Kishkun // Rynok transportnyh uslug (problemy povysheniya effektivnosti): Mezhd. sb. nauchn. tr. 2017. - Vyp. 10. - S. 326-333.

Материал поступил в редакцию 19.02.2021 